\title{
Human prion protein sequence elements impede cross-species chronic wasting disease transmission
}

\author{
Timothy D. Kurt, ${ }^{1}$ Lin Jiang, ${ }^{2}$ Natalia Fernández-Borges, ${ }^{3}$ Cyrus Bett, ${ }^{1}$ Jun Liu, ${ }^{1}$ Tom Yang, ${ }^{1}$ Terry R. Spraker, ${ }^{4}$ Joaquin Castillaa, ${ }^{3,5}$ \\ David Eisenberg, ${ }^{2}$ Qingzhong Kong, ${ }^{6}$ and Christina J. Sigurdson ${ }^{1,7}$ \\ 'Departments of Pathology and Medicine, UCSD, La Jolla, California, USA. UCLA-DOE Institute, Howard Hughes Medical Institute, and Molecular Biology Institute, UCLA, Los Angeles, California, USA. \\ ${ }^{3} \mathrm{CIC}$ bioGUNE, Derio, Spain. ${ }^{4}$ Department of Microbiology, Immunology and Pathology, Colorado State University, Fort Collins, Colorado, USA. ${ }^{5}$ IKERBASQUE, Basque Foundation for Science, Bilbao, Spain. \\ ${ }^{6}$ Departments of Pathology and Neurology, and National Center for Regenerative Medicine, Case Western Reserve University, Cleveland, Ohio, USA. \\ 7Department of Pathology, Microbiology, and Immunology, UCD, Davis, California, USA.
}

\begin{abstract}
Chronic wasting disease (CWD) is a fatal prion disease of North American deer and elk and poses an unclear risk for transmission to humans. Human exposure to CWD occurs through hunting activities and consumption of venison from prioninfected animals. Although the amino acid residues of the prion protein (PrP) that prevent or permit human CWD infection are unknown, NMR-based structural studies suggest that the $\beta 2-\alpha 2$ loop (residues 165-175) may impact species barriers. Here we sought to define PrP sequence determinants that affect CWD transmission to humans. We engineered transgenic mice that express human PrP with four amino acid substitutions that result in expression of PrP with a $\beta 2-\alpha 2$ loop (residues 165-175) that exactly matches that of elk PrP. Compared with transgenic mice expressing unaltered human PrP, mice expressing the human-elk chimeric PrP were highly susceptible to elk and deer CWD prions but were concurrently less susceptible to human Creutzfeldt-Jakob disease prions. A systematic in vitro survey of amino acid differences between humans and cervids identified two additional residues that impacted CWD conversion of human PrP. This work identifies amino acids that constitute a substantial structural barrier for CWD transmission to humans and helps illuminate the molecular requirements for cross-species prion transmission.
\end{abstract}

\section{Introduction}

Infectious prions cause rapidly progressive, fatal neurodegenerative diseases that can be transmitted zoonotically. For example, bovine spongiform encephalopathy (BSE) prions spread from cattle to humans, causing 229 human deaths from variant Creutzfeldt-Jakob disease (vCJD) as of June 2014 (1-3). In North America, chronic wasting disease (CWD) in deer and elk spreads by horizontal transmission and is remarkably infectious, with a reported incidence of $89 \%$ in one captive population (4). Human exposure to CWD prions likely occurs through consumption of venison from CWD-infected deer (5), as both muscle and fat from deer have been shown to contain infectious prions $(6,7)$. An active surveillance of more than 17,000 US residents revealed that nearly $20 \%$ hunt deer or elk, and more than two-thirds have consumed venison (8), yet the risk of developing a prion infection through dietary exposure to CWD remains unclear. Human prion proteinexpressing (PrP-expressing) transgenic mice resist CWD infection, suggesting a strong barrier for CWD transmission to humans (9-12); however, certain non-human primates are CWD susceptible (13-16). Similarly conflicting results from studies performed in vitro showed that CWD prions either efficiently or poorly convert human PrP to a pathogenic isoform $(14,17-19)$. Thus, no consen-

Conflict of interest: The authors have declared that no conflict of interest exists. Submitted: October 21, 2014; Accepted: January 8, 2015.

Reference information: / Clin Invest. 2015;125(4):1485-1496. doi:10.1172/JCI79408. sus has emerged on the susceptibility of humans to CWD prions, and the transmission of CWD to humans remains a major public health concern.

Cross-species prion transmission is influenced by (a) the sequence similarity between the cellular prion protein $\left(\operatorname{PrP}^{\mathrm{C}}\right)$ and the misfolded, aggregated conformer $\left(\mathrm{PrP}^{\mathrm{sc}}\right)$ and $(\mathrm{b})$ the $\operatorname{PrP}^{\mathrm{Sc}}$ conformation (20). $\mathrm{PrP}^{\mathrm{C}}$ has an unstructured $\mathrm{N}$ terminus and a globular C-terminal domain, arranged in three $\alpha$-helices and a short anti-parallel $\beta$-sheet, together comprising approximately 210 amino acids (21). The tertiary structure of $\operatorname{PrP}^{\mathrm{C}}$ is highly conserved among mammals; however, specific amino acid differences between species are hypothesized to impact the intermolecular binding of $\operatorname{PrP}^{\mathrm{C}}$ and $\mathrm{PrP}^{\mathrm{Sc}}$ (22). One segment of high sequence diversity is the $\beta 2-\alpha 2$ loop, consisting of residues 165-175 (human numbering) in which only 3 amino acids (P165, Y169, and Q172) are strictly conserved $(23,24)$.

Nuclear magnetic resonance-based (NMR-based) structural studies suggest that residue differences within the $\beta 2-\alpha 2$ loop and the $\mathrm{C}$ terminus would preserve the global shape of $\mathrm{PrP}$ but may alter surface hydrogen bonding patterns that influence protein-protein interactions (22). Indeed, $\beta 2-\alpha 2$ loop substitutions were shown to impair prion conversion in vitro (25-28) and in vivo, as transgenic mice that express PrP with 168R or with Y169G, S170N, and N174T substitutions resist infection with mouse-adapted prions $(29,30)$. Collectively, these studies provide a rationale for investigating the role of the $\beta 2-\alpha 2$ loop in barriers to human infection with CWD. 
A

Human (120) AVVGGLGGYMLGSAMSRPIIHFGSDYEDRYYRENMHR

Elk

Elk

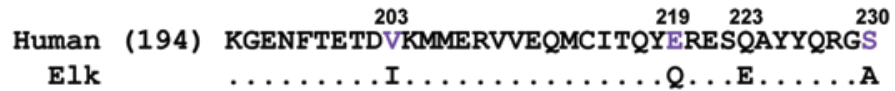

B

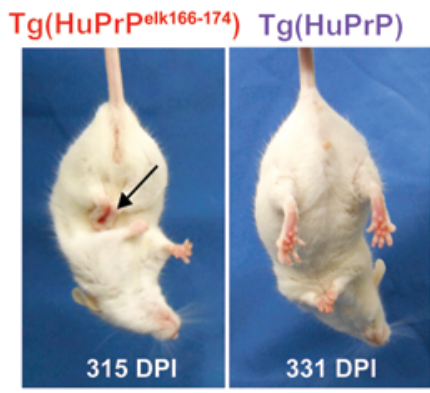

CWD-inoculated

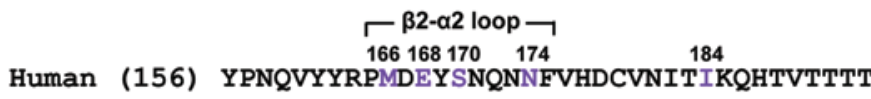


Figure 1. Mice expressing a human-elk chimeric PrPc are infected by CWD prions. (A) Human PrPc sequence with elk residue differences shown below. The human residue Q223 is also present in mule deer, but is E223 in elk. Amino acid substitutions present in the $\operatorname{Tg}(\mathrm{HuPrPelk166-174)}$ mice are in red. (B) Neurologic signs in CWD-inoculated $\mathrm{Tg}(\mathrm{HuPrPelk166-174})$ mice included hind limb clasp (arrow) typical of prion disease, whereas the hind limb splay of $\mathrm{Tg}(\mathrm{HuPrP})$ mice was normal. (C) Kaplan-Meier survival curves of CWD-inoculated $\mathrm{Tg}(\mathrm{HuPrPelk16-174})$ mice reveal a significant decrease in the incubation period on second passage. One mouse died with intercurrent disease at $109 \mathrm{dpi}$. No $\mathrm{Tg}(\mathrm{HuPrP})$ mice developed clinical signs of infection after CWD inoculation. Prion infection status was confirmed by biochemical and histologic assays. P1 and P2, passages 1 and 2. (D) Diffuse PrPsc deposition, spongiform degeneration (arrowheads) (H\&E), and astrogliosis (GFAP) localize to the thalamus of deer or elk CWD-inoculated $\mathrm{Tg}$ (HuPrPelk166-174) mice, but do not occur in elk CWD-inoculated $\operatorname{Tg}(\mathrm{HuPrP})$ mice. Scale bar: $50 \mu \mathrm{m}$. (E) The CJD-inoculated $\operatorname{Tg}(\mathrm{HuPrP})$ mice manifested neurologic signs, including a stiff tail (arrow), by 173 dpi. (F) $\operatorname{Tg}(\mathrm{HuPrP})$ mice inoculated with human SCJD prions developed terminal disease by $186 \mathrm{dpi}$, whereas $\operatorname{Tg}($ HuPrPelk166-174) animals developed terminal disease between 260 and 290 dpi. ${ }^{* *} P<0.01 ;{ }^{* *} P<0.001$; log-rank (Mantel-Cox) test.

We engineered transgenic mice expressing human $\mathrm{PrP}^{\mathrm{C}}$ with four elk amino acid substitutions at positions 166, 168, 170 , and 174 within the $\beta 2-\alpha 2$ loop and inoculated the mice with CWD prions from elk and deer. Here we show that the humanelk chimeric mice were highly susceptible to CWD infection yet showed a delayed disease progression after exposure to human CJD prions. Testing other human-cervid residue differences in vitro revealed that only residues 143 and 155 further impacted human $\operatorname{PrP}^{\mathrm{C}}$ conversion by CWD. Last, we provide evidence that the amyloid-forming propensity of key segments of $\mathrm{PrP}^{\mathrm{C}}$ promotes prion conversion, even when PrP sequence differences exist. Taking these data into the context of prior work on microcrystal structures of the $\beta 2-\alpha 2$ loop, we propose a structural mechanism for the barriers underlying interspecies prion transmission. Together our results reveal specific amino acids that impair CWD transmission to humans as well as a new determinant for cross-species prion transmission.

\section{Results}

Engineering transgenic mice expressing a human-elk chimeric PrP construct. We developed transgenic mice expressing human PrP with four amino acid residues from elk PrP on a Prnp $p^{-/}$background (Figure 1A), referred to as $\operatorname{Tg}\left(\mathrm{HuPr}^{\mathrm{elk} 166-174}\right)$ mice. Transgenic mice expressing human $\operatorname{PrP}[\operatorname{Tg}(\mathrm{HuPrP})]$ were used as controls (9), and the same plasmid vector was used to generate the two transgenic mouse lines. $\mathrm{The} \operatorname{Tg}\left(\mathrm{HuPrP} \mathrm{P}^{\text {elk16-174 }}\right)$ mice and the $\mathrm{Tg}(\mathrm{HuPrP})$ control mice had comparable $\operatorname{PrP}^{\mathrm{C}}$ levels in the brain, i.e., approximately 1- to 2-fold higher than those of WT mice (Supplemen- 
A

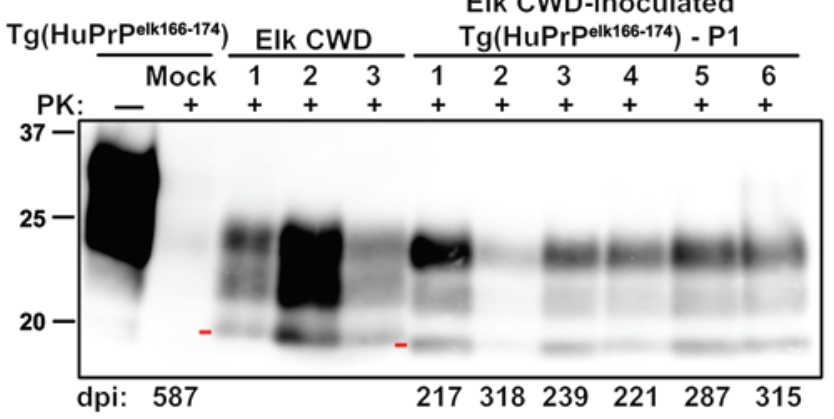

C
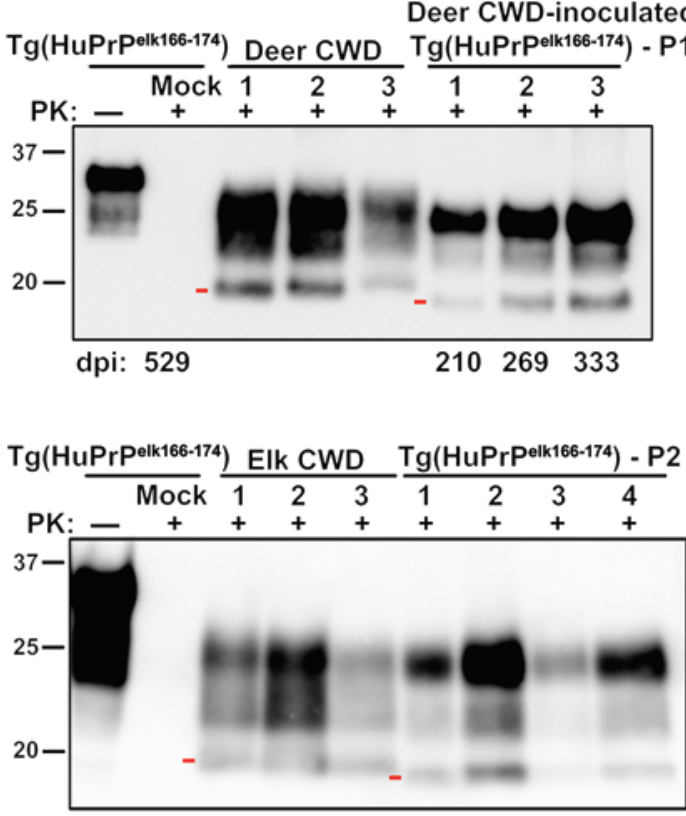

dpi: 587

$\begin{array}{llll}173 & 183 & 198 & 258\end{array}$
B

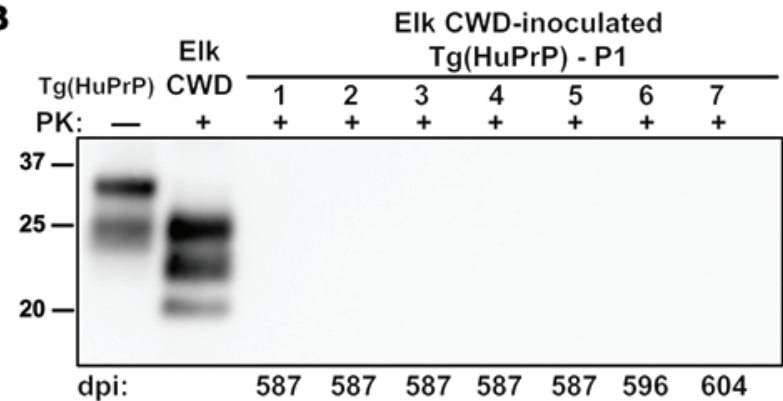

D

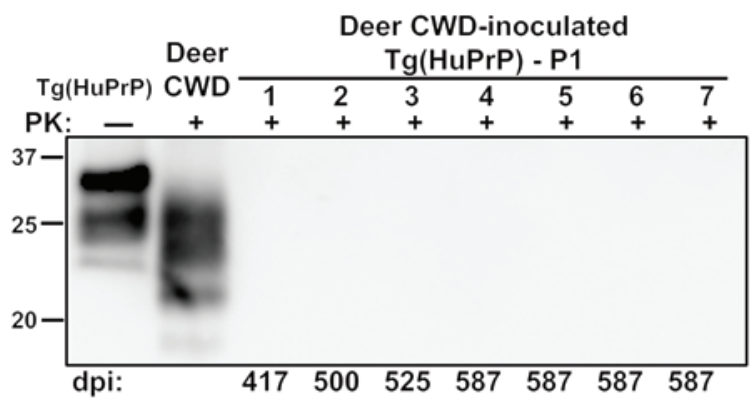

F

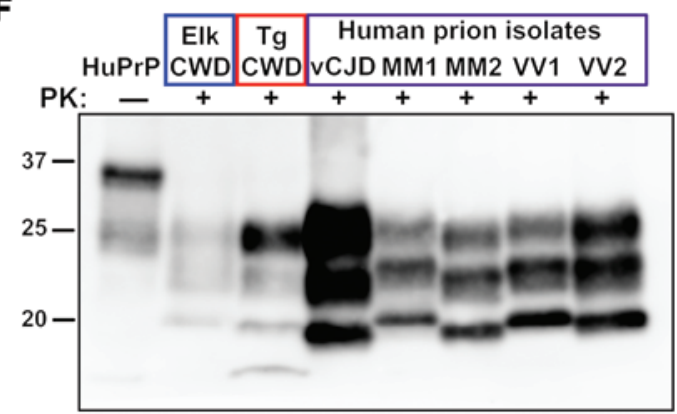

G

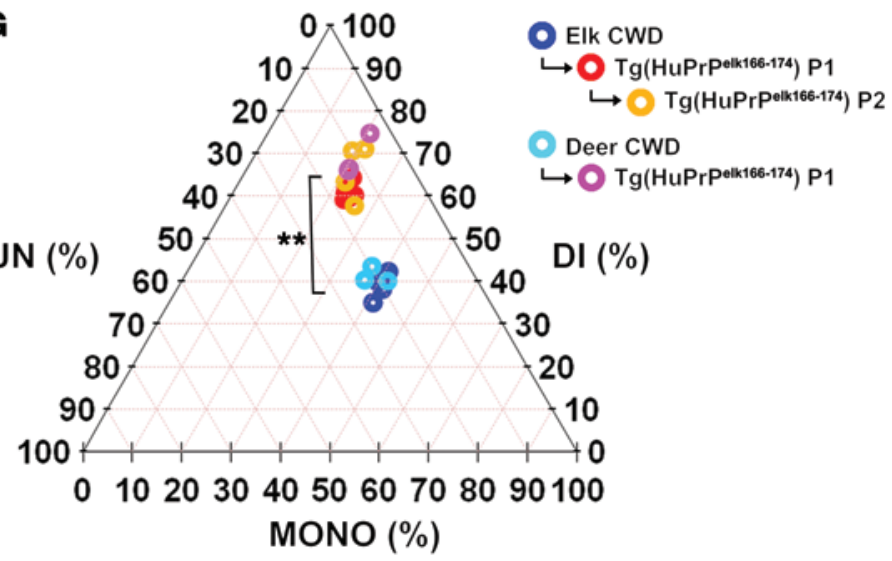

Figure 2. CWD prions differ biochemically in Tg(HuPrPelk166-174) mice as compared with cervid CWD or human CJD. (A) $\mathrm{PrP}^{\mathrm{Sc}}$ from $\mathrm{Tg}(\mathrm{HuPrP}$ elk166-174) brain migrates faster and has a glycoform pattern (ratio of di-, mono-, and un-glycosylated PrPsc) different from that of elk CWD by Western blot analysis. Results for six of the seven positive mice are shown here. Red dashes indicate migration of unglycosylated $\mathrm{PrP}^{\mathrm{sc}}$. (B) In Tg(HuPrP) mice inoculated with elk CWD, the brain shows no detectable PrPsc, even after NaPTA precipitation. (C) Tg(HuPrPelk166-174) mice infected with deer CWD show a PrPsc electrophoretic migration and glycoform pattern indistinguishable from that of $\mathrm{Tg}(\mathrm{HuPrPelk16-174})$ mice inoculated with elk CWD. (D) As in B, no Tg(HuPrP) mice inoculated with deer CWD have detectable PrPSc in the brain. (E) Sub-passaged CWD-Tg(HuPrPek166-174) (P2) in Tg(HuPrPelk166-174) mice revealed no change in the electrophoretic mobility or glycoform pattern of $\operatorname{PrP}^{\mathrm{Sc}}$ as compared with $\mathrm{PrP}^{\mathrm{Sc}}$ from P1. (F) Comparison of $\mathrm{Tg}(\mathrm{HuPrP}$ elk166-174)-CWD prions with human sporadic and variant CJD prions. Isolates consisted of type 1 or type 2 sporadic CJD prions from individuals homozygous for methionine (MM) or valine (VV) at PRNP codon 129; Tg CWD, CWD-infected Tg(HuPrPelk166-174). (C) Measurements of di-, mono-, and un-glycosylated PrPsc from CWD-inoculated $\operatorname{Tg}\left(\right.$ HuPrPelk166-174) mice differed significantly from those of CWD-infected elk and deer. ${ }^{* *} P<0.01 ; 2$-tailed, unpaired Student's $t$ test comparing ratio of di- and monoglycosylated $\operatorname{PrP}(n=3-6$ animals per group). 
tal Figure 1A; supplemental material available online with this article; doi:10.1172/JCI79408DS1). We confirmed that $\operatorname{PrP}^{\mathrm{C}}$ in $\mathrm{Tg}\left(\mathrm{HuPrP} \mathrm{P}^{\mathrm{elk} 166-174}\right)$ mice was processed similarly to WT PrP, as both were glycosylated and anchored in lipid rafts together with flotillin (Supplemental Figure 1B). Since certain transgenic mice expressing mutant $\operatorname{PrP}$ develop spontaneous prion disease, we examined 29 aged $\operatorname{Tg}\left(\mathrm{HuPrP} \mathrm{P}^{\mathrm{elk} 166-174}\right)$ mice (350-676 days old), yet found no evidence of prion disease. Mice had no evidence of neurological impairment, PrP deposits on histologic sections, or PrP aggregates detected by biochemical assays (Supplemental Figure 1C).

$\mathrm{Tg}\left(\mathrm{HuPrP} \mathrm{P}^{\text {elk16-174 }}\right)$ mice develop CWD prion infection. We inoculated $\operatorname{Tg}\left(\mathrm{HuPrP} \mathrm{P}^{\mathrm{elk} 166-174}\right)$ and $\operatorname{Tg}(\mathrm{HuPrP})$ mice with CWD prions from a naturally infected elk or with uninfected cervid brain (mock control). Animals were examined every other day for behavioral changes or neurologic impairment. None of the $\operatorname{Tg}(\mathrm{HuPrP})$ mice inoculated with elk prions developed clinical disease by $\geq 587$ days after inoculation $(n=12)$ (Figure 1, B and C), consistent with previous reports (9). Three of 12 mock-inoculated $\mathrm{Tg}\left(\mathrm{HuPrP} \mathrm{P}^{\mathrm{elk} 166-174}\right)$ mice died of non-prion-related causes. In contrast, 7 of 8 (88\%) $\mathrm{Tg}\left(\mathrm{HuPrP} \mathrm{Plk166-174}^{\mathrm{i}}\right)$ mice inoculated with elk CWD prions manifested terminal signs of neurologic disease, including immobility, progressive weight loss, hind leg clasp, and disorientation (268 \pm 16 days post-inoculation [dpi], mean \pm SEM) (Figure 1 , B and $\mathrm{C}$, and Supplemental Videos). $\mathrm{Tg}\left(\mathrm{HuPr} \mathrm{P}^{\text {elk166-174}}\right)$ mice were also susceptible to mule deer prions ( 3 of 4 mice infected, incubation period $271 \pm 35 \mathrm{dpi})$.

$\mathrm{Tg}\left(\mathrm{HuPr} \mathrm{P}^{\text {elk166-174}}\right)$ mice show a delay in developing human prion infection. We reasoned that the new elk $\beta 2-\alpha 2$ loop sequence in human PrP may have created a barrier to human sporadic CJD (sCJD) prions, and therefore we inoculated $\mathrm{Tg}\left(\mathrm{HuPrP} \mathrm{P}^{\text {elk166-174 }}\right)$ and $\operatorname{Tg}(\mathrm{HuPrP})$ mice with sCJD. Subsequently, all $\operatorname{Tg}(\mathrm{HuPrP})$ mice developed terminal prion disease by $177 \pm 3$ dpi $(n=6)$, whereas all $3 \mathrm{Tg}\left(\mathrm{HuPr} \mathrm{P}^{\text {elk166-174 }}\right)$ mice developed terminal prion disease by $280 \pm 10 \mathrm{dpi}$, an approximately $60 \%$ lengthening of the incubation period (Figure 1, E and F, and Supplemental Figure 2). These findings indicate that elk residues at positions 166, 168, 170, and 174 of human PrP enable CWD-induced conversion yet delay the development of terminal CJD infection.

Thalamic and hypothalamic prion deposits in CWD-infected $\mathrm{Tg}\left(\mathrm{HuPr} \mathrm{P}^{\mathrm{elk166-174}}\right)$ mice. Neuropathologic assessment of brains from CWD-inoculated $\operatorname{Tg}\left(\mathrm{HuPrP} \mathrm{P}^{\mathrm{ek} 166-174}\right)$ mice showed lesions typical of prion disease, including focal spongiform change, gliosis, and diffuse and punctate $\mathrm{PrP}^{\mathrm{Sc}}$ deposits in the thalamus and hypothalamus (Figure 1D). Lesions were specific to CWD-inoculated $\operatorname{Tg}\left(\mathrm{HuPrP}\right.$ elk166-174 $^{-1}$ mice, since CWD-inoculated $\operatorname{Tg}(\mathrm{HuPrP})$ mice lacked spongiform change, gliosis, or $\mathrm{PrP}^{\mathrm{sc}}$ deposition (Figure 1D). We also compared the distribution of brain lesions in CWDinfected $\mathrm{Tg}\left(\mathrm{HuPrP} \mathrm{elk166-174}^{-1}\right.$ mice with those in transgenic mice expressing cervid PrP (same promoter). The lesion distribution in the $\operatorname{Tg}\left(\mathrm{HuPrP} \mathrm{P}^{\mathrm{elk} 166-174}\right)$ mice differed profoundly from the distribution in transgenic mice expressing cervid $\operatorname{PrP}[\mathrm{Tg}(\mathrm{CerPrP})$ mice] that were CWD-inoculated in a previous study (9). Although $\operatorname{PrP}^{\mathrm{C}}$ was widely expressed, the $\mathrm{Tg}\left(\mathrm{HuPrP} \mathrm{P}^{\text {elk166-174 }}\right)$ mice showed lesions restricted primarily to the thalamus and hypothalamus, whereas the $\operatorname{Tg}(\mathrm{CerPrP})$ mice showed severe, widespread spongiform changes in the cerebral cortex, hippocampus (dentate gyrus), and putamen, with severe neuronal loss in the cerebellum (9).
The proteinase K-resistant (PK-resistant) core of PrP, a hallmark of prion infection, was detected biochemically in all elk CWD-inoculated $\operatorname{Tg}\left(\mathrm{HuPrP}^{\mathrm{elk166-174}}\right)$ mice with terminal disease $(n=7)$ but in none of the $\mathrm{Tg}(\mathrm{HuPrP})$ mice (Figure 2, A and $\mathrm{B})$. Inoculation with deer CWD produced similar results in $\operatorname{Tg}\left(\mathrm{HuPrP} \mathrm{P}^{\text {elk166-174 }}\right)$ and $\operatorname{Tg}(\mathrm{HuPrP})$ mice (Figure 2, C and D). Thus, the CWD-inoculated $\operatorname{Tg}\left(\mathrm{HuPrP} \mathrm{P}^{\mathrm{elk} 166-174}\right)$ mice presented the classic features of prion disease in the brain, both histopathologically and biochemically. HuPrPelk166-174-CWD prions from one infected mouse were inoculated into $\mathrm{Tg}(\mathrm{HuPrP})$ and $\mathrm{Tg}\left(\mathrm{HuPrP} \mathrm{elk166-174}^{\mathrm{i}}\right)$ mice. No clinical or biochemical evidence of prion disease was detected in any $\operatorname{Tg}(\mathrm{HuPrP})$ mice by 545 dpi $(n=5)$, whereas all $\mathrm{Tg}\left(\mathrm{HuPrP}\right.$ elk166-174$^{-1}$ mice developed terminal prion disease by $203 \pm 19 \mathrm{dpi}(n=4)$, indicating that a substantial barrier exists between the two groups despite the fact that they differ by only 4 residues.

Human-elk chimeric prions show altered biochemical properties as compared with elk CWD prions. The $\mathrm{PrP}^{\mathrm{sc}}$ conformation may be preserved or changed profoundly when transmitted to a species with a different PrP sequence (31). We therefore compared the biochemical properties of HuPrPelk166-174-CWD with those of elk CWD prions and found consistent evidence supporting the former's unique conformation. First, the electrophoretic mobility of PK-resistant HuPrPelk166-174-CWD increased, indicating a smaller PK-resistant core (Figure 2, A and C), which also differed from human sporadic and variant CJD (Figure 2F). Second, in

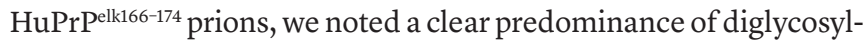
ated $\mathrm{PrP}^{\mathrm{sc}}$, whereas elk prions contained nearly equal proportions of di- and monoglycosylated $\operatorname{PrP}^{\mathrm{Sc}}$ (60:20:20 versus 40:40:20, di-, mono-, and unglycosylated $\mathrm{PrP}^{\mathrm{sc}}$, respectively) (Figure $2 \mathrm{G}$ ). Third,

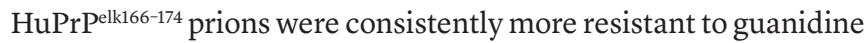
$\mathrm{HCl}$-induced (Gdn-HCl-induced) unfolding (32) than elk CWD (Figure 3, A-C). Last, the relative levels of PK-resistant $\mathrm{PrP}^{\mathrm{Sc}}$ differed; HuPrPelk166-174 prions were composed of approximately twothirds PK-resistant $\operatorname{PrP}^{\mathrm{Sc}}(66 \% \pm 5 \%$; mean \pm SEM), whereas elk contained 3-fold less PK-resistant $\operatorname{PrP}^{\mathrm{Sc}}(20 \% \pm 3 \%)$ (Figure 3, D and E, and Supplemental Figure 3). These four independent measures indicated that elk and HuPrPelk166-174 CWD vary biochemically, consistent with a change in the CWD conformation upon conversion to the human-elk chimeric sequence. The elk residues also modified the CJD glycoform profile (Figure 3, F and G), an outcome that lends further support to the concept that the $\beta 2-\alpha 2$ loop region impacts $\mathrm{PrP}^{\mathrm{C}}-\mathrm{PrP}^{\mathrm{Sc}}$ interactions.

We next investigated adaptation of the new human-elk chimeric prions by further passaging in $\mathrm{Tg}\left(\mathrm{HuPrP} \mathrm{P}^{\text {elk166-174 }}\right)$ and $\mathrm{Tg}(\mathrm{HuPrP})$ mice. Sub-passage of HuPrPelk166-174 prions in $\operatorname{Tg}\left(\mathrm{HuPrP} \mathrm{P}^{\text {elk166-174}}\right)$ mice revealed no significant change in the electrophoretic mobility, glycoform pattern (Figure 2E), or $\mathrm{PrP}^{\mathrm{Sc}}$ deposition sites (Supplemental Figure 4), indicating that the dominant conformation was preserved. Notably, the incubation period decreased significantly $(24 \%, P<0.05$, Student's $t$ test) upon second passage. To assess whether these findings could be reproduced in vitro in a conversion assay, we performed protein misfolding cyclic amplification (PMCA) using brains from the $\mathrm{Tg}\left(\mathrm{HuPrP} \mathrm{P}^{\text {elk166-174}}\right)$ and $\mathrm{Tg}(\mathrm{HuPrP})$ mice as $\operatorname{PrP}^{\mathrm{C}}$ substrates. Indeed, the HuPrPelk166-174 was converted by CWD within five rounds, whereas the HuPrP was not converted by CWD, even after 10 rounds of amplification (Table 1 and Supplemental Figure 5). 
A

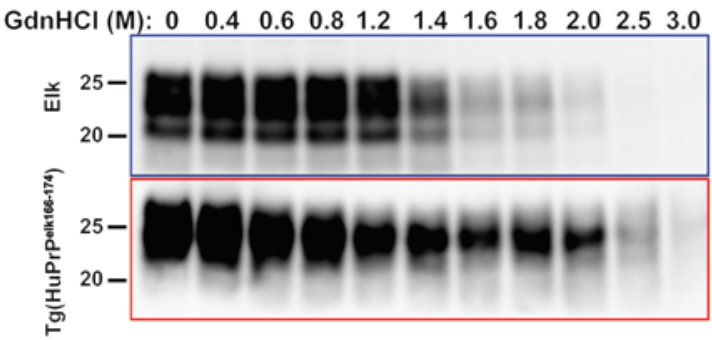

B

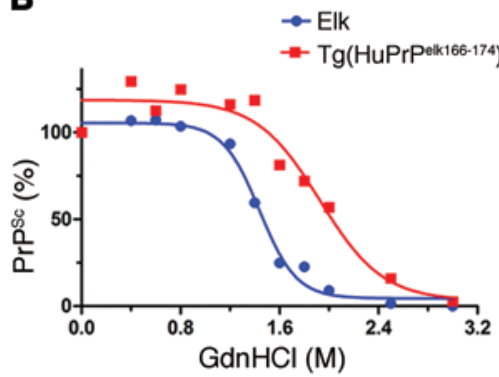

C

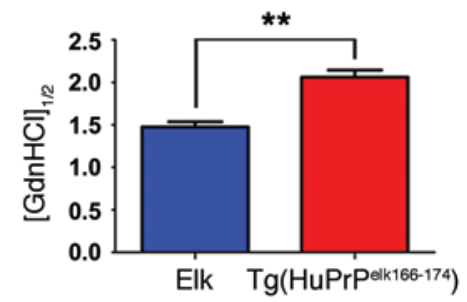

D

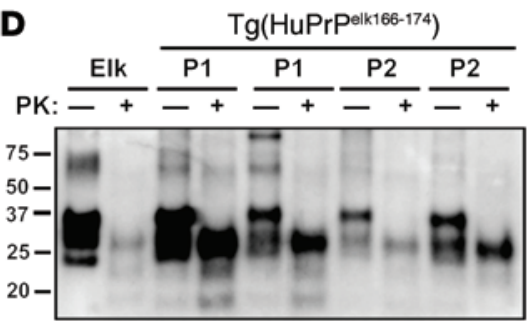

E

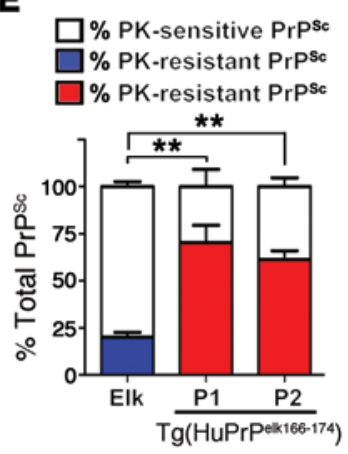

$\mathbf{F}$ CJD-inoculated $\mathrm{Tg}(\mathrm{HuPrP})$ mice

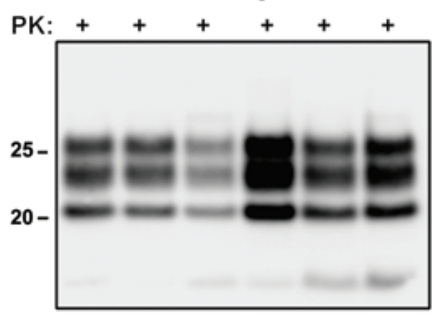

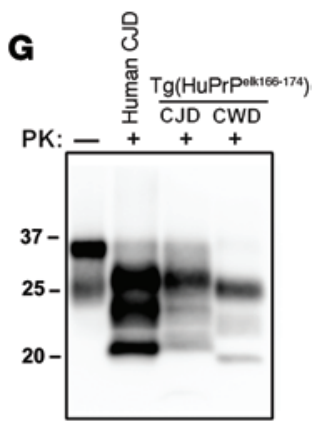

Figure 3. $\mathrm{Tg}$ (HuPrPelk166-174)-CWD prions display increased stability in chaotropes and resistance to enzyme degradation as compared with elk CWD. PrPsc stability as assessed by guanidine hydrochloride (GdnHCl) denaturation was significantly greater in $\operatorname{Tg}\left(\mathrm{HuPrP} \mathrm{Pelk166-174}^{\mathrm{S}}\right.$ mice than in elk. (A) Western blots and (B) denaturation curves show a representative example from four independent experiments. (C) The bar graph shows the $\mathrm{GdnHCl}$ concentration at which half the PrP has been PK-digested $\left([\mathrm{GdnHCl}]_{1 / 2}\right)(n=4$ mice and 4 replicates of one elk); results are from four experiments (mean \pm SEM). (D) PrPsc was separated from PrPc by size exclusion chromatography, then samples were split and either treated or not treated with PK and analyzed by Western blot. (E) Quantification of blots shows that significantly more PrPsc is PK resistant in Tg(HuPrPelk166-174) mice than in elk. (F) Brain homogenates from Tg(HuPrP) mice inoculated with sCjD prions show PK-resistant PrP ${ }^{\text {sc }}$ by Western blot. (G) Brain homogenates from $\operatorname{Tg}\left(\right.$ HuPrPelk16-174) mice inoculated with $\mathrm{SCJD}$ or CWD prions show different PK-resistant PrP ${ }^{\mathrm{sc}}$ migration patterns. ${ }^{* *} P<0.01$, 2-tailed, unpaired Student's $t$ test.

$168 Q$ and $170 N$ substitutions markedly reduce the barrier for CWD conversion of human PrP. To address how each of the four residue substitutions impacts conversion by CWD prions, we generated human $\operatorname{PrP}^{\mathrm{C}}$ having single elk substitutions at positions 166, 168, 170, or 174 in a PrPC -deficient RK13 cell line. Cell lysates containing the human $\operatorname{PrP}^{\mathrm{C}}$ variants or cervid $\operatorname{PrP}^{\mathrm{C}}$ were seeded with elk CWD prions and subjected to repeated cycles of sonication for 24 hours in a cell lysate-based PMCA assay $(26,33,34)$, which previously reproduced in vivo prion susceptibility (28). Here, we found that HuPrP with either the E168Q or S170N substitution was converted by CWD, albeit at low levels (17\%-26\%) relative to conversion of cervid $\operatorname{PrP}^{\mathrm{C}}$ (Figure 4, $\mathrm{A}$ and $\left.\mathrm{B}\right)$. We next tested HuPrP with elk substitutions at 168 and 170 together, and found remarkably robust conversion equivalent to that of cervid $\operatorname{PrP}^{\mathrm{C}}$ (Figure 4, C and D). Intriguingly, HuPrP with elk substitutions at positions $166,168,170$, and 174 resulted in only approximately $10 \%$ conversion, revealing more efficient conversion in HuPrP with two versus four elk substitutions (Figure 4, C and D).

Since the efficiency of cross-species prion conversion depends on amino acid sequence similarity, the less-efficient conversion with four versus two residue substitutions was surprising and unexpected. As residue 166 interacts with the C-terminal segment of helix $\alpha 3$ (residues 218-226) (35), we tested whether a long-range interaction between residues 166 and 219, where human and cervid PrP differ, could explain the low con- version efficiency. Thus, we next measured conversion of HuPrP with elk residues at $166,168,170,174$, as well as 219 , yet found only a negligible increase in conversion with the addition of the 219 substitution (Figure 4, C and D), suggesting that the previous results were due to local effects within the $\beta 2-\alpha 2$ loop. Further testing of $\mathrm{HuPrP}$ with elk residues at 166,168 , and 170 , or at 168,170 , and 174, revealed that the N174T elk substitution was impairing CWD-induced conversion of human-elk chimeric PrP (Figure 4, C and D).

We noted that together, the E168Q and S170N elk substitutions in $\mathrm{HuPrP}$ created an asparagine- and glutamine-rich, highly aggregation-prone $\beta 2-\alpha 2$ loop sequence (QYNNQNNF, from 168 to 175) identical to that of bank vole, a species known to be remarkably susceptible to prions from many different species (36). Thus, these data collectively suggest that a highly aggregation-prone $\beta 2-\alpha 2$ loop segment can override $\operatorname{PrP}^{\mathrm{Sc}}-\mathrm{PrP}^{\mathrm{C}}$ amino acid sequence mismatches. We propose that prion conversion between two species is determined not only by (a) PrP amino acid sequence similarity and (b) $\mathrm{PrP}^{\mathrm{Sc}}$ conformation, but also (c) the amyloid-forming propensity of key segments of the host $\mathrm{PrP}^{\mathrm{C}}$ protein.

Positions 143 and 155 also impact the CWD species barrier. To identify other amino acids that impact CWD-seeded conversion of human $\operatorname{PrP}^{\mathrm{C}}$, we generated human $\operatorname{PrP}^{\mathrm{C}}$ having the single elk substitutions I138L, S143N, H155Y, I184V, and V203I. At each cervid polymorphic site, the human PrP sequence matched the cervid 
Table 1. Summary of CWD- and CJD-seeded conversion of HuPrPelk16--174 and HuPrP by PMCA

\begin{tabular}{|c|c|c|c|c|c|c|c|c|c|c|c|}
\hline \multirow[b]{2}{*}{ Seed } & \multirow[b]{2}{*}{ Substrate } & \multicolumn{10}{|c|}{ PMCA round number ${ }^{A}$} \\
\hline & & 1 & 2 & 3 & 4 & 5 & 6 & 7 & 8 & 9 & 10 \\
\hline CWD1 & $\operatorname{Tg}(\mathrm{HuPrP})$ & ND & ND & $0 / 4$ & $0 / 4$ & $0 / 4$ & $0 / 4$ & $0 / 4$ & $0 / 4$ & $0 / 4$ & $0 / 4$ \\
\hline CWD1 & $\operatorname{Tg}(\mathrm{HuPrP}$ elk166-174) & ND & ND & $0 / 4$ & $0 / 4$ & $4 / 4$ & $4 / 4$ & $4 / 4$ & $4 / 4$ & $4 / 4$ & $4 / 4$ \\
\hline CWD2 & $\operatorname{Tg}(\mathrm{HuPrP})$ & ND & ND & $0 / 4$ & $0 / 4$ & $0 / 4$ & $0 / 4$ & $0 / 4$ & $0 / 4$ & $0 / 4$ & $0 / 4$ \\
\hline CWD2 & $\operatorname{Tg}(\mathrm{HuPrPelk166-174})$ & ND & ND & $0 / 4$ & $0 / 4$ & $3 / 4$ & $4 / 4$ & $4 / 4$ & $4 / 4$ & $4 / 4$ & $4 / 4$ \\
\hline CJD & $\operatorname{Tg}(\mathrm{HuPrP})$ & ND & ND & $2 / 2$ & $2 / 2$ & $2 / 2$ & $2 / 2$ & $2 / 2$ & $2 / 2$ & $2 / 2$ & $2 / 2$ \\
\hline CJD & $\operatorname{Tg}(\mathrm{HuPrP} \mathrm{Plk166-174})$ & ND & ND & $2 / 2$ & $2 / 2$ & $2 / 2$ & $2 / 2$ & $2 / 2$ & $2 / 2$ & $2 / 2$ & $2 / 2$ \\
\hline No seed & $\operatorname{Tg}(\mathrm{HuPrP})$ & ND & ND & $0 / 2$ & $0 / 2$ & $0 / 2$ & $0 / 2$ & $0 / 2$ & $0 / 2$ & $0 / 2$ & $0 / 2$ \\
\hline No seed & $\operatorname{Tg}(\mathrm{HuPrP}$ elk166-174) & ND & ND & $0 / 2$ & $0 / 2$ & $0 / 2$ & $0 / 2$ & $0 / 2$ & $0 / 2$ & $0 / 2$ & $0 / 2$ \\
\hline
\end{tabular}

${ }^{A}$ Representative results of two experiments in which samples were seeded with either of two CWD isolates (CWD1 and CWD2) or the MM1 subtype of CJD. The number of positive samples (bold) is shown as a fraction of the total replicates per experiment.

residue associated with highest CWD susceptibility (G96, M132, and S225 [cervid numbering]); thus, these sites were not modified. Cell lysates containing the $\operatorname{PrP}^{\mathrm{C}}$ variants were then seeded with elk CWD prions and subjected to cell lysate PMCA. Of these variants, only human PrP with an S143N or H155Y substitution showed more than $5 \%$ of the level of cervid $\mathrm{PrP}^{\mathrm{C}}$ conversion, at $19 \%$ and $15 \%$, respectively (Figure 4, E and F), suggesting that human residues S143 and H155 also contribute to the CWD to human transmission barrier.

\section{Discussion}

In 1996, ten cases of new variant CJD were reported in the UK with suspected links to the BSE epidemic $(37,38)$, and extensive evidence now supports that cattle BSE crossed the species barrier and infected humans $(39,40)$. With the realization that animal prions could transmit to humans, concerns arose that CWD in cervids may lead to cases of a novel form of CJD. Nevertheless, four laboratories have independently reported that transgenic mice expressing human PrP resist CWD infection, suggestive of a strong barrier to infection (9-12). Here we have identified the specific residues in human PrP that modulate CWD transmission. We report that CWD transmits to mice expressing a human-elk chimeric $\operatorname{PrP}^{\mathrm{C}}$ and show that the CWD-human species barrier is largely maintained by the humanspecific amino acids within the $\beta 2-\alpha 2$ loop. Within the loop, human residues E168 and S170 are significant inhibitors of CWD conversion, as evidenced by in vitro conversion experiments. Human residues S143 and H155 likely also contribute to the CWD barrier. Collectively, these results help define the structural barriers that limit CWD transmission to humans.

Elucidating the determinants of cross-species prion transmission. Prions can transmit between different species; however, infection of a new species is typically characterized by prolonged, variable incubation periods and low attack rates $(41,42)$. Known determinants of interspecies prion conversion are (a) $\mathrm{PrP}^{\mathrm{C}}$ and $\mathrm{PrP}^{\mathrm{Sc}}$ sequence similarity and (b) the conformation of the infectious prion $(43,44)$. Here we propose to add a third determinant, the presence of glutamines or asparagines in host $\mathrm{PrP}^{\mathrm{C}}$ within key interaction segments. These key segments will vary depending upon exposure in the $\mathrm{PrP}^{\mathrm{sc}}$ conformation. We found that human PrP with the E168Q and S170N substitutions was readily converted by CWD, whereas adding the N174T substitution, which increases homology with elk CWD but removes an asparagine, paradoxically led to a massive decrease in conversion. These results suggest that for CWD, the $\beta 2-\alpha 2$ segment is accessible and interacts with host $\mathrm{PrP}^{\mathrm{C}}$. These data also indicate that the presence of N/Qs in the loop can be a strong determinant for conversion that overrides certain sequence differences.

Glutamine- and asparagine-rich protein segments are proposed to play a role in protein aggregation due to side chain hydrogen bonding among amide groups that stabilizes adjacent $\beta$-strands (45-47). Asparagine residues are prevalent in the $\operatorname{PrP}^{\mathrm{C}}$ of bank voles, a species that is highly susceptible to CWD, sheep scrapie, and CJD, despite having many $\operatorname{PrP}^{\mathrm{C}}$ sequence mismatches with these infectious prions (48-51). Indeed, bank voles were recently designated the "universal acceptor for prions" (36). Similar to the bank vole, hamsters are susceptible to CWD and other prions $(42,52-54)$ and also have an N/Q-rich loop. Thus, it is possible that the bank vole-like sequence in the human $\beta 2-\alpha 2$ loop creates a permissive host $\operatorname{PrP}^{\mathrm{C}}$ sequence that is converted by prions from other species, despite sequence mismatches. Consistent with the observation that N/Q residues lead to a lower species barrier, fewer N/Qs in key segments may be protective, as polymorphisms that replace a single N/Q residue - for example, Q168R in sheep $\operatorname{PrP}^{\mathrm{C}}(55,56), \mathrm{Q} 219 \mathrm{~K}$ in mouse $\operatorname{PrP}^{\mathrm{C}}(30)$, and Q219K in goat $\operatorname{PrP}^{\mathrm{C}}$ (57) (all human numbering) - correlate with profound resistance to certain prions in vivo.

Accumulating evidence suggests that the $\beta 2-\alpha 2$ loop governs certain prion transmission barriers and conformational properties, reminiscent of Sup35 yeast prion segments, also shown to govern species barriers and strains (58). In transgenic mice, S170N and N174T loop substitutions increased susceptibility to CWD and hamster prions, led to resistance to sheep or cattle prions, and altered the RML mouse prion conformation (59). Here we show that replacing four human amino acids in the $\beta 2-\alpha 2$ loop enabled infection with elk CWD and created a partial barrier for human CJD, as evidenced by the delayed infection kinetics. Additionally, HuPrPelk166-174-CJD showed a different glycosylation pattern as compared with human CJD prions, suggesting the emergence of a new CJD conformation. Surprisingly, passage of $\mathrm{HuPrP} \mathrm{elk}^{\mathrm{e} 166-174}$-CWD prions revealed efficient infection of all $\mathrm{Tg}\left(\mathrm{HuPrP} \mathrm{Pelk6-174}^{\mathrm{e}}\right)$ mice, but not $\mathrm{Tg}(\mathrm{HuPrP})$ mice, despite only four amino acid differences in PrP. 
A
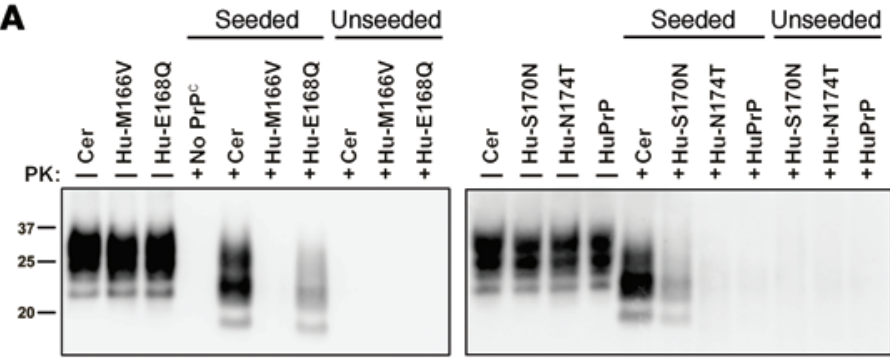

Seeded Unseeded
B

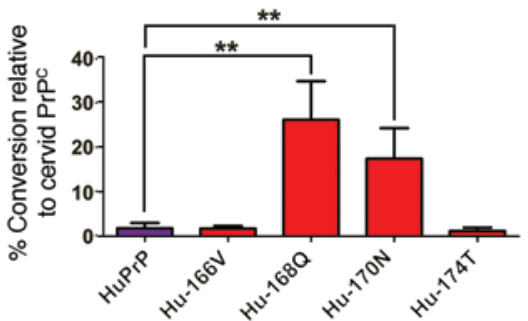

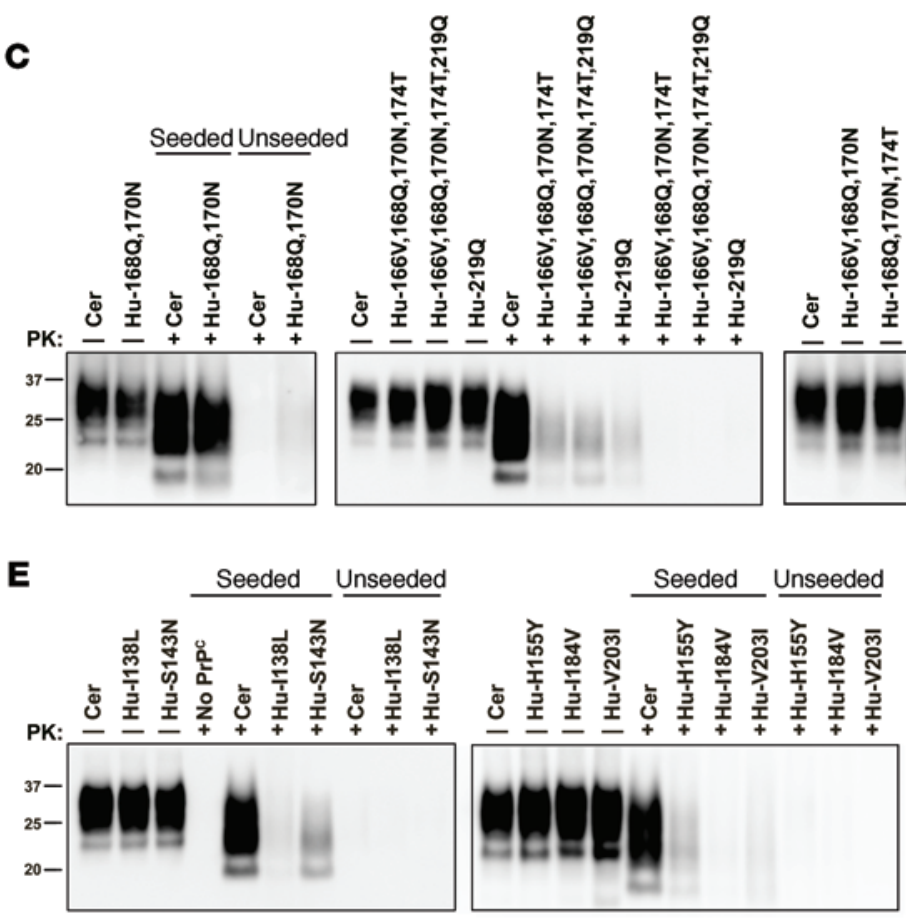

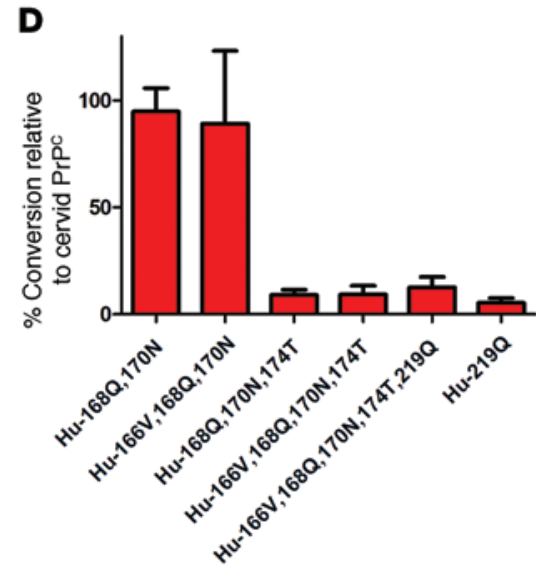

Seeded Unseeded
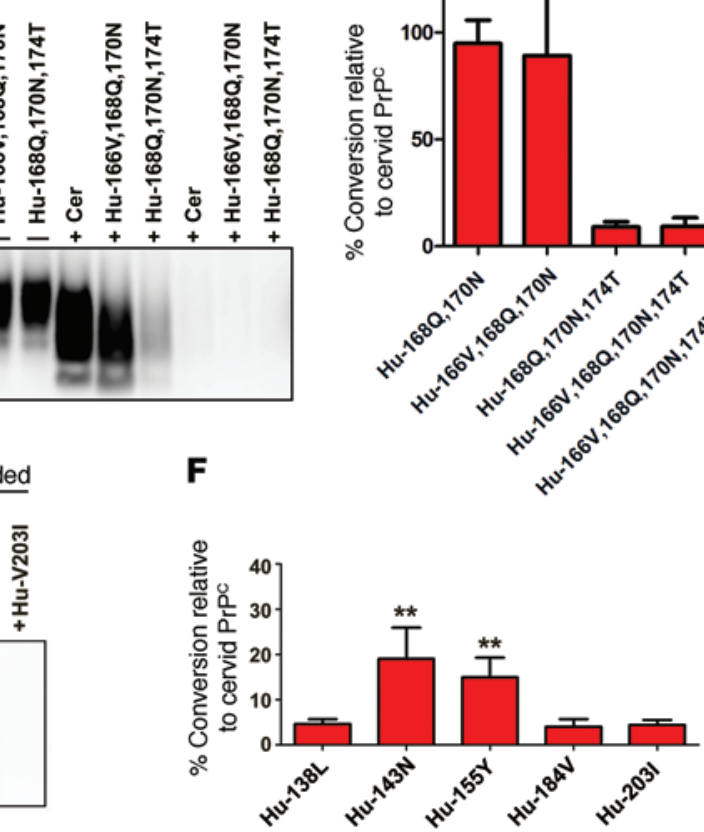

Figure 4. Two elk residue substitutions in the $\beta 2-\alpha 2$ loop of human PrPC enable $100 \%$ conversion by CWD prions in a cell lysate-based PMCA. (A) CWDseeded conversion of human PrPc with a single M166V, E168Q, S170N, or N174T substitution showed conversion of HuPrP-168Q and HuPrP-170N. Human $\operatorname{PrP}^{\complement}$ was not converted by CWD prions. Samples without PK show that PrPc levels were equivalent. Cer, cervid. (B) Quantification of CWD-seeded human PrPc variants relative to cervid PrPc. (C) CWD-seeded conversion of HuPrP-168Q,170N and cervid PrPc showed similar levels of conversion. (D) Quantification of CWD-seeded human PrPc variants relative to cervid PrPc. The conversion of HuPrP-168Q,170N and HuPrP-166V,1680,170N was not significantly different than that of cervid PrPc. (E) CWD-seeded conversion of human PrPC with a single M138L, S143N, H155Y, I184V, or V203I substitution. (F) Quantification of CWD-seeded human PrPc variants relative to cervid PrPc In $\mathbf{A}$ and $\mathbf{E}$, the "No PrP" lane shows untransfected RK13 cell lysate that was seeded and subjected to PMCA as a control. There was no detection of the seed as shown here. ${ }^{* *} P<0.01,2$-tailed, unpaired Student's $t$ test, relative to conversion of $\operatorname{HuPrP}(n=3-6$ experimental replicates each).

A proposed structural mechanism for the CWD-to-human transmission barrier. How do short PrP segments control prion conversion? Microcrystal structures of segments from amyloid-like fibers invariably reveal pairs of tightly packed $\beta$-sheets, in which complementary side chains interdigitate in a dry "steric zipper" interface (60). We hypothesize that efficient prion conversion requires donor and recipient PrP loop segments to form a tight steric zipper, whereas side chain mismatches lead to steric clashes and cavities, prevent conversion, and may account for species barriers in prion disease $(61,62)$. Consistent with this hypothesis, microcrystal structures of human and cervid $\beta 2-\alpha 2$ loop segments belong to different classes of steric zippers $(60,62)$, and our computational analysis suggests that the human and cervid loop segments do not form complementary steric zippers (Figure 5, Supplemental Figure 6, and Supplemental
Table 1). We found that the S170 (human) and N170 (elk) side chains leave a cavity within the zipper core due to poor packing (Figure 5 and Supplemental Figure 6). Also, the E168 (human) and Q168 (elk) residues sterically clash, which hinders tight, highly complementary side chain interactions between $\beta$-sheets in the zipper models (Figure 5 and Supplemental Figure 6). In summary, the zipper models suggest that residue mismatches between human and elk PrP at positions 168 and 170 would not support efficient conversion and may explain our results at the atomic level.

In conclusion, we have identified the $\beta 2-\alpha 2$ loop sequence of human $\operatorname{PrP}^{\mathrm{C}}$ as a major barrier to $\operatorname{PrP}$ conversion by CWD prions. The human-specific residues in the $\beta 2-\alpha 2$ loop, particularly E168 and S170, appear to substantially raise the energetic barrier for conversion of human PrP by CWD prions, making conversion of 
A

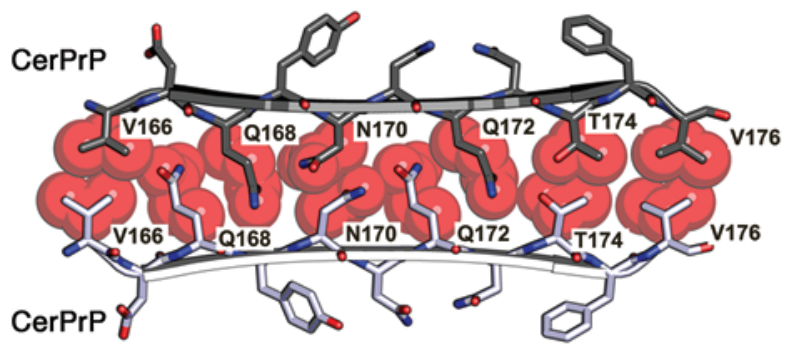

B

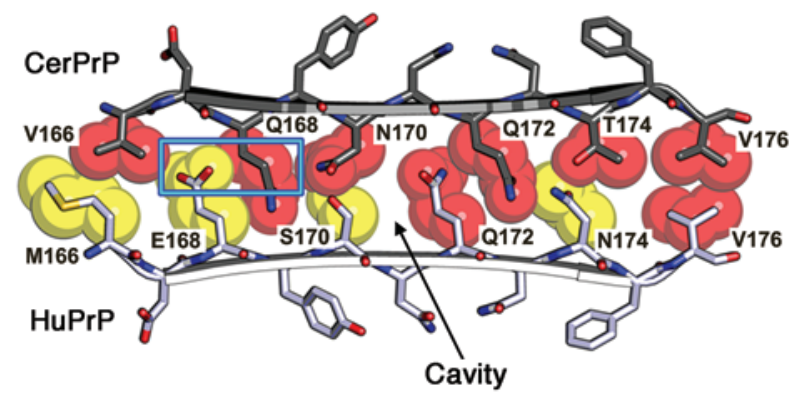

C

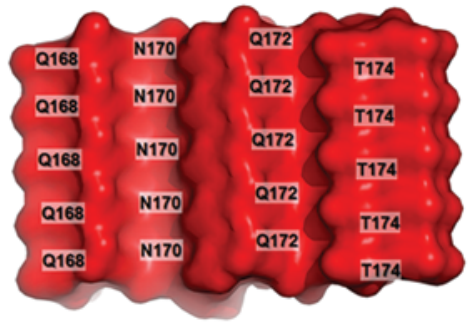

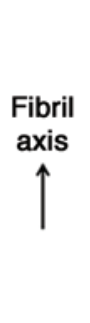

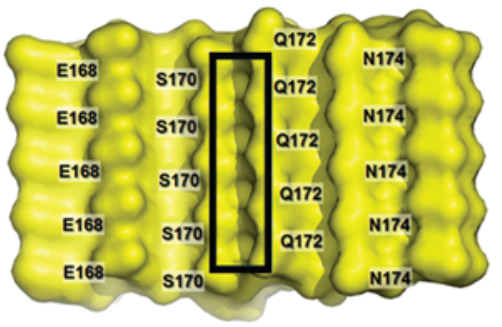

D

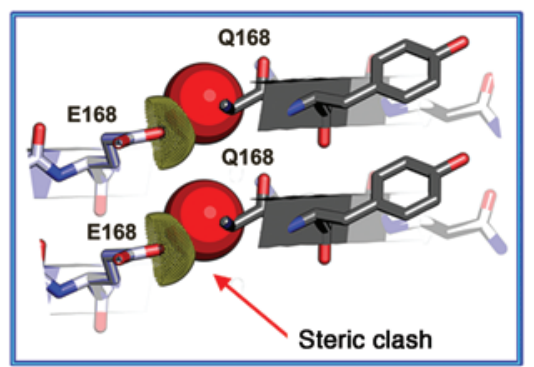

Figure 5. Atomic space-filling and surface representations of the PrP loop highlight the side chain interactions at the zipper interface. (A) Atomic spacefilling model illustrates the view down the fibril axis. The amino acid side chains of donor cervid $\operatorname{PrP}$ (gray) and recipient cervid PrP (white) interdigitate in a class 3 steric zipper. (B) In contrast, the zipper interactions between the donor cervid PrP (gray) and the recipient human $\operatorname{PrP}$ (white), which contain yellow side chains (M166, E168, S170, N174), generate a cavity (arrow) between human S170 and cervid N170, as well as steric clash (blue rectangle) between human residue E168 and cervid residue Q168. (C) A side view of the surface of the cervid PrP loop modeled as a $\beta$-sheet (red). The interacting $\beta$-sheet has been removed to provide a clear view of the interface. A similar side view of the $\beta$-sheet surface of the human PrP loop (yellow) reveals cavities near residue S170 in the core of the zipper interface (black rectangle). (D) A magnified, rotated view of the inset in B shows the clash between human residue E168 (yellow) and cervid residue Q168 (red).

human PrP highly unfavorable. Thus we propose the $\beta 2-\alpha 2$ loop as a critical initial $\mathrm{PrP}^{\mathrm{C}}-\mathrm{PrP}^{\mathrm{sc}}$ interaction site during the templating of human $\operatorname{PrP}^{\mathrm{C}}$ by either CWD or CJD prions. Although we cannot exclude the involvement of additional PrP segments that include 143 and 155 , the $\beta 2-\alpha 2$ loop may act as an important gatekeeper that promotes or impairs conversion, depending on the sequence (58). Since the loop substitutions in human PrP also markedly delayed infection with CJD, the $\beta 2-\alpha 2$ loop segment may also be a key site for $\mathrm{PrP}^{\mathrm{C}}$-CJD prion interaction and may indicate a potential therapeutic target for rationally designed stable peptides (63, 64) or inhibitors that block $\operatorname{PrP}^{\mathrm{C}}-\mathrm{PrP}^{\mathrm{Sc}}$ interaction and impede the progression of prion disease.

\section{Methods}

Generation of transgenic mice. Development of the $\operatorname{Tg}(\mathrm{HuPrP})$-expressing mice was previously described (9). Constructs for the $\mathrm{HuPrP} \mathrm{elk166-174}^{\mathrm{e}}$ transgenes were based on the same human $\mathrm{PrP}$ in the half-genomic plasmid (pHGPRP) used for the $\operatorname{Tg}(\mathrm{HuPrP})$ mice $(9,65)$. Site-directed mutagenesis was performed to replace the sequence coding for 166 , 168,170 , and 174 . The final construct was confirmed by sequencing. One error-free clone was chosen for the creation of transgenic mice by pronuclear microinjection, performed at the UC San Diego Transgenic Mouse Core facility. Founder pups were screened by tail DNA PCR using the following primers: forward, 5'-CAACCGAGCTGAAGCATTC; reverse, 5'-CCCTCTCGTACTGGGTGATAC. All founder mice that carried the transgene were bred with $\mathrm{FVB} / \mathrm{Prnp} p^{o / 0}$ mice (provided by Stanley Prusiner's laboratory, UCSF, San Francisco, California, USA) to achieve transgenic mice with a $P r n p^{o / 0}$ back- ground. Zygosity of the $\operatorname{Tg}\left(\mathrm{HuPr} \mathrm{P}^{\text {elk166-174}}\right)$ mice was determined by TaqMan qPCR performed at the UC Davis Mouse Biology Program. PrP expression in the brains of transgenic and WT mice was assessed by Western blot analysis using the anti-PrP monoclonal antibody POM19 (provided by Adriano Aguzzi, University Hospital of Zurich, Zurich, Switzerland) (66). Mice were maintained under specific pathogen-free conditions.

Prion inoculations. WT (FVB), $\operatorname{Tg}\left(\mathrm{HuPrP}^{\text {elk166-174 }}\right)$, or $\operatorname{Tg}(\mathrm{HuPrP})$ (homozygous mice generated from the previously reported $\mathrm{Tg} 40$ ) transgenic mice (groups of $n=4-10$ mice) were intracerebrally inoculated into the left parietal cortex with 20-30 $\mu$ of brain homogenate $(1 \%-5 \%)$ containing CWD prions from a naturally infected elk or mule deer previously shown to contain infectious prions (67) or from a human with sporadic CJD. Uninfected brain homogenates were inoculated into mice of the same genotypes as negative controls. Mice were monitored three times weekly, and TSE was diagnosed according to clinical criteria including ataxia, kyphosis, stiff tail, hind leg clasp, and hind leg paresis. Mice were sacrificed at the onset of terminal neurologic disease when showing such signs as weight loss, tremors, slow movements, and severe kyphosis, or at approximately 600 dpi. Incubation period was calculated as the day of inoculation to the day of terminal clinical disease.

Sodium phosphotungstic acid precipitation and Western blotting. $10 \%$ brain homogenates from all prion-inoculated mice were prepared in PBS using a Beadbeater tissue homogenizer (BioSpec Products). Samples were subjected to sodium phosphotungstic acid (NaPTA) precipitation as previously described (68). Briefly, 25-100 $\mu$ l aliquots of $10 \%$ brain homogenate were mixed with an equal volume of $4 \%$ sar- 
kosyl and digested with an endonuclease (Benzonase, Sigma-Aldrich), followed by treatment with $20 \mu \mathrm{g} / \mathrm{ml}$ proteinase $\mathrm{K}$ at $37^{\circ} \mathrm{C}$ for 30 minutes. After the addition of $\mathrm{NaPTA}, \mathrm{MgCl}_{2}$, and protease inhibitors (Complete-TM, Roche), extracts were incubated at $37^{\circ} \mathrm{C}$ for $30 \mathrm{~min}$ utes and centrifuged at $18,000 \mathrm{~g}$ for 30 minutes at $37^{\circ} \mathrm{C}$. Pellets were resuspended in LDS loading buffer (Invitrogen), and samples were heated to $95^{\circ} \mathrm{C}$ prior to electrophoresis through a $10 \%$ Bis-Tris gel (Invitrogen) and transferred to a nitrocellulose membrane by wet blotting. Proteins were detected with anti-PrP antibodies 3F4 (MAB1562, Millipore) and POM19 (66), followed by an HRP-conjugated antimouse IgG antibody (Jackson ImmunoResearch Laboratories Inc.). Signals were visualized using a chemiluminescent substrate (Supersignal West Dura, Thermo Scientific) and an LAS-4000 imager (Fujifilm). Prion-infected or uninfected brain samples were also subjected to NaPTA precipitation and blotting to serve as controls.

Histopathology and immunohistochemistry. Five-micrometer-thick sections were cut onto positively charged glass slides and stained with hematoxylin and eosin or immunostained using antibodies for glial fibrillary acidic protein (GFAP). For GFAP staining, sections were deparaffinized, rehydrated, and quenched with 3\% hydrogen peroxide for 10 minutes. Sections were then incubated in $20 \mu \mathrm{g} / \mathrm{ml}$ PK for 10 minutes, blocked, and incubated with anti-GFAP monoclonal antibody (M0761, Dako) for 45 minutes, followed by biotinylated anti-mouse IgG (Jackson ImmunoResearch Laboratories Inc.) for 30 minutes, streptavidin-HRP (Jackson ImmunoResearch Laboratories Inc) for 30 minutes, and DAB substrate for 7 minutes. Sections were counterstained with hematoxylin.

Paraffin-embedded tissue blots. Five-micrometer-thick sections were collected onto $0.45-\mu \mathrm{m}$ nitrocellulose membranes (Bio-Rad) and dried at room temperature overnight and then at $55^{\circ} \mathrm{C}$ for 30 minutes. Membranes were then incubated in xylene and serially rehydrated in $100 \%$ isopropanol, $70 \%$ isopropanol, and distilled water with $0.1 \%$ Tween-20 for 10 minutes each. To improve tissue adherence, membranes were dried. After a brief rinse with TBST (10 mM Tris- $\mathrm{HCl}$ [pH 7.8], $100 \mathrm{mM} \mathrm{NaCl}, 0.05 \%$ Tween-20), membranes were incubated in $50 \mu \mathrm{g} / \mathrm{ml} \mathrm{PK}$ in $10 \mathrm{mM}$ Tris- $\mathrm{HCl}$ (pH 7.8), $100 \mathrm{mM} \mathrm{NaCl}$, and $0.1 \%$ Brij- 35 at $56^{\circ} \mathrm{C}$ for 16 hours; washed twice in TBST; incubated in $4 \mathrm{M}$ guanidine isothiocyanate in $10 \mathrm{mM}$ Tris$\mathrm{HCl}$ for 30 minutes; and washed in TBST. Membranes were blocked in casein (Sigma-Aldrich) and immunolabeled with anti-PrP monoclonal antibody 12F10 (189710, Cayman Chemical) for 2 hours, biotinylated goat anti-mouse IgG (Jackson ImmunoResearch Laboratories Inc.) for 1 hour, streptavidin-HRP (Jackson ImmunoResearch Laboratories Inc.) for 30 minutes, and DAB substrate for 5 minutes. Color development was stopped in distilled water, and membranes were dried overnight.

$P M C A$. In vitro prion replication experiments were performed as previously described (69). Briefly, $50 \mu \mathrm{l}$ of brain homogenate from $\operatorname{Tg}\left(\mathrm{HuPrP} \mathrm{P}^{\text {elk166-174 }}\right)$ and $\operatorname{Tg}(\mathrm{HuPrP})$ mice was seeded with $5 \mu \mathrm{l}$ CWD or sporadic CJD prion seed and subjected to sonication (model S-700MPX, QSonica). The sonicator settings were: 20 seconds at a power setting of $70 \%-80 \%$ followed by 30 minutes of incubation for a total of 24 hours for each round, performed at $37-38^{\circ} \mathrm{C}$. Up to ten serial rounds of PMCA were performed. To test for $\operatorname{PrP}^{\mathrm{sc}}$, all sonicated samples were digested with $50-100 \mu \mathrm{g} / \mathrm{ml} \mathrm{PK}$ for 1 hour at $42^{\circ} \mathrm{C}$ and analyzed by Western blot. Blots were probed with anti-PrP monoclonal antibody 6H4 (01-010, Prionics). Two experimental PMCA repeti- tions were performed on brain homogenates from $\operatorname{Tg}\left(\mathrm{HuPrP} \mathrm{P}^{\text {elk166-174}}\right)$ and $\operatorname{Tg}(\mathrm{HuPrP})$ mice using brain from a single CWD-infected mule deer (CWD1) and brains from a pool of 28 CWD-infected mule deer (CWD2) to seed separate reactions, with four replicates analyzed in each experiment.

Cell lysate-based PMCA. Cervid Prnp (G96, M132, S225, Q226 [cervid numbering]) and human PRNP (M129) in the pcDNA3.1C vector (Invitrogen) containing the 3F4 epitope tag (109M, 112M) were generated by site-directed mutagenesis as previously described (28). PrP contained the highly conserved amino-terminal coding sequence (residues 23-111) of cervid Prnp and the cervid alanine residue at position 230. Site-directed mutagenesis (Agilent) was used to generate an array of cervid Prnp and human PRNP plasmids, each with amino acid substitutions as described in Results. Human PRNP with the M112V was not generated, as this would have removed the $3 \mathrm{~F} 4$ epitope used for detection. The final constructs were confirmed by sequencing. The M132 genotype (cervid numbering) of the elk CWD seed material was verified by standard PCR and sequencing (primers: forward, 5'-CTGACACCCTCTTTATTTTG; reverse, 5'-CTATCCTACTATGAGAAAAATG). Confluent, PrP-deficient RK13 cells (ATCC) were transfected with 4-5 $\mu \mathrm{g}$ of plasmid DNA using Lipofectamine 2000 (Invitrogen). At 24 hours after transfection, cells were washed twice, harvested in $1 \mathrm{ml} \mathrm{PBS}$, and centrifuged at 1,000 $\mathrm{g}$ for 1 minute. The pellet was resuspended in PMCA buffer (PBS containing 1\% Triton $\mathrm{X}-100,0.05 \%$ saponin, $150 \mathrm{mM} \mathrm{NaCl}$, and $5 \mathrm{mM} \mathrm{EDTA}$ ), passed twice through a 27 -gauge needle, and clarified by centrifugation at 2,000 $\mathrm{g}$ for 1 minute.

For the PMCA reaction, $45 \mu$ l of RK13 cell lysate was seeded with 5 $\mu$ l of CWD-infected elk brain homogenate and subjected to sonication with the following settings: 5 seconds at a power setting of 50\%-60\%, followed by 10 minutes of incubation for 24 hours, with continuous rotation at $37^{\circ} \mathrm{C}$. Samples were digested with $100 \mu \mathrm{g} / \mathrm{ml} \mathrm{PK}$ for 30 minutes at $37^{\circ} \mathrm{C}$ and analyzed by Western blot for PrP using anti$\operatorname{PrP}$ monoclonal antibody $3 \mathrm{~F} 4$. $\operatorname{PrP}^{\mathrm{C}}$ levels were measured in lysates by blotting $1 \mu \mathrm{l}$ from samples seeded with CWD-negative elk brain homogenate together with the seeded samples. Signals were quantified using a Fujifilm LAS-4000 imager and Multi Gauge software. For quantification of conversion efficiency, the PK-resistant PrP for each $\mathrm{PrP}^{\mathrm{C}}$ mutation was compared with control samples according to the formula $\left[\left(\operatorname{Pr} P^{S c} / \operatorname{Pr} P^{C}\right)_{\text {mutant }} /\left(\operatorname{Pr} P^{S c} / \operatorname{Pr} P^{C}\right)_{\text {cervid }}\right] \times 100$. Experiments in which $\operatorname{PrP}^{\mathrm{C}}$ densitometric signals were within $0.8-2 \times$ the cervid $\operatorname{PrP}^{\mathrm{C}}$ signal were used for quantification, and no $\operatorname{PrP}^{\mathrm{C}}$ concentration-dependent effects were observed within this range. Lysates seeded with uninfected elk brain were included in all experiments, and no signals were observed in these samples. At least 3 experimental replicates were performed.

Velocity gradient sedimentation. $10 \%$ brain homogenates prepared in PBS containing 9\% sucrose and protease inhibitors (CompleteMini, Sigma-Aldrich) were centrifuged at $750 \mathrm{~g}$ for 5 minutes at $4^{\circ} \mathrm{C}$. Supernatant was mixed with an equal volume of $2 \%$ Triton X-100 in PBS containing $9 \%$ sucrose. Samples were brought to a final concentration of $40 \%$ OptiPrep (Sigma-Aldrich) using flotation buffer, then overlaid with $30 \%$ and $5 \%$ OptiPrep prepared using flotation buffer (10 mM MES containing 1\% Triton X-100, 2 mM EDTA, 1 mM DTT, and protease inhibitors). All steps were performed on ice. Samples were centrifuged at 200,000 $\mathrm{g}$ for 18 hours at $4^{\circ} \mathrm{C}$ using an MLA-80 rotor (Beckman-Coulter). Fractions 1-13 were collected from top to bottom. 
Size exclusion chromatography of $\operatorname{PrP}^{\text {Sc }}$. CWD-infected elk and CWDinfected $\mathrm{Tg}\left(\mathrm{HuPrP} \mathrm{P}^{\text {elk166-174}}\right)$ mouse brain homogenates were digested using Benzonase (Millipore) with $50 \mathrm{mM} \mathrm{MgCl}_{2}$ for 20 minutes at $37^{\circ} \mathrm{C}$, mixed with $1 \%$ sarkosyl for 20 minutes at $37^{\circ} \mathrm{C}$, and centrifuged at 2,000 $\mathrm{g}$ for 5 minutes. Supernatants were injected onto a Fast Performance Liquid Chromatography (FPLC) column (Superose 6, 3.2/30, GE Healthcare Life Sciences) using running buffer (50 mM sodium acetate [pH 8.5] containing $0.1 \%$ sarkosyl) at a flow rate of $60 \mu \mathrm{l} / \mathrm{min}$, and 24 fractions were collected. Fractions 2-23 from CWD-infected or uninfected elk and CWD-infected or uninfected $\operatorname{Tg}\left(\mathrm{HuPrP} \mathrm{P}^{\mathrm{elk} 166-174}\right)$ mice were subjected to SDS-PAGE, followed by Western blotting using anti-PrP antibodies POM19 (elk) and 3F4 (mice).

15B3 immunoprecipitation for $\mathrm{PrP}^{\mathrm{sc}}$-specific detection. To semiquantitatively measure $\mathrm{PrP}^{\mathrm{sc}}$ in FPLC fractions, $\mathrm{PrP}^{\mathrm{C}}$ - and $\mathrm{PrP}^{\mathrm{sc}}$-containing fractions (fractions 1-7 and fractions 8-24, respectively) were each pooled and analyzed for $\mathrm{PrP}^{\mathrm{sc}}$. Pooled fractions were incubated in PBS and protease inhibitors (Roche), $0.1 \%$ sarkosyl, and rat anti-mouse Dynabeads (Invitrogen) overnight at $22^{\circ} \mathrm{C}$ with rotation to remove proteins that bind to unlabeled beads. Beads were removed, and each sample was incubated with anti-PrP antibody 15B3-conjugated Dynabeads for 3 hours at $22^{\circ} \mathrm{C}$ with rotation. The beads were washed four times with wash buffer $(10 \mathrm{mM}$ Tris- $\mathrm{HCl}$ [pH 7.4] containing $1 \%$ Triton $\mathrm{X}-100,150 \mathrm{mM} \mathrm{NaCl}$, and $5 \mathrm{mM}$ EDTA) and boiled in loading dye for 5 minutes prior to SDS-PAGE and detection using biotinylated monoclonal antibody POM1 (66).

Computational analysis of zipper models for PrP conversion. To understand the molecular mechanism of cross-species prion transmission, we sought structural models of elk and human PrP side chains within the $\beta 2-\alpha 2$ loop to explain the affects of different amino acid substitutions on CWD conversion in vitro. The modeling strategy was similar to one that was previously described (28). The zipper structure of PrP peptides was built using Rosetta software (https://www.rosettacommons.org/). The segments were modeled as a parallel $\beta$-sheet by using the template backbone structures of both the elk prion NNQNTF (PDB code 3FVA; ref. 70) and the yeast prion Sup35 GNNQQNY zipper (PDB code 1YJP; ref. 71). The pair of $\beta$-sheets was assembled by exploring all four possible arrangements (class 1-3; the class 1 zipper structure has 2 arrangements) (60). The zipper structure of PrP peptides was then refined by simultaneously optimizing the rigid-body degree of freedom between the $\beta$-sheets, side chain and backbone torsions of each $\beta$-strand, guided by full-atom Rosetta energy functions. Taking advantage of the recently developed symmetry implementation in Rosetta, the fibril symmetry of each peptide subunit is restrained to assure that symmetrical geometry is satisfied during the whole optimization process. Finally, the models were ranked based on Rosetta full-atom energy (the sum of Lennard-Jones potential for nonbond interactions, implicit solvation energy, hydrogen bond energy, and others) and the packing (shape complementary score and buried solvent-accessible surface area) between $\beta$-sheets. Two final zipper models with strongest predicted Rosetta energy and best shape complementary score were selected (classes 1 and 3).

For each selected final structure (classes 1 and 3), the amino acid substitutions were introduced by RosettaDesign. The new models for each substitution were optimized using the same refinement procedure. The Rosetta full-atom energy and the packing between $\beta$-sheets for different substitutions were calculated. The analysis and scores of the class 3 zipper structure are summarized in Supplemental Table 1.

Statistics. $P$ values of less than 0.05 were considered statistically significant. The incubation periods for groups of prion-infected mice were compared by log-rank (Mantel-Cox) test. The average incubation period upon first and second passage of elk CWD in $\operatorname{Tg}\left(\mathrm{HuPrP} \mathrm{P}^{\text {elk166-174 }}\right)$ mice was additionally compared by a 2-tailed Student's $t$ test. The ratios of di- and monoglycosylated $\mathrm{PrP}^{\mathrm{Sc}}$ and $\mathrm{PrP}^{\mathrm{Sc}}$ stability in prioninfected brains were assessed by 2-tailed unpaired Student's $t$ tests. Results from in vitro conversion experiments ( $n=3-6$ experimental replicates) using human PrP variants were compared by 2-tailed unpaired Student's $t$ test. All data are presented as mean \pm SEM unless otherwise noted.

Study approval. All procedures involving live animals were approved by the UC San Diego IACUC (protocol number S08037).

\section{Acknowledgments}

We thank Michael Oldstone, Edward Hoover, and Steven Gonias for helpful discussions; Gary Landucci, Donald Forthal, and Alan Barbour for biosafety support and discussions; Tran Phan for excellent technical support; and the animal caretakers at UCSD and UC Irvine. We thank Jean Jewell for CWD inocula used in the PMCA experiments. This study was supported by the NIH (NSO55116, NS069566, NS076896, and U54AIO359 [to C.J. Sigurdson] and AG029430 [to D.S. Eisenberg]), national grants from Spain (AGL2012-37988-C04-01, CTP2013-P05, and EFA205/11 [to J. Castilla]) and a fellowship from the Morris Animal Foundation (D13ZO-419 to T.D. Kurt).

Address correspondence to: Christina J. Sigurdson, Department of Pathology, UC San Diego, 9500 Gilman Dr., La Jolla, California 92093-0612, USA. Phone: 858.534.0978; E-mail: csigurdson@ ucsd.edu.
1. Centers for Disease Control and Prevention. Fact sheet: Variant Creutzfeldt-Jakob disease. http:// www.cdc.gov/ncidod/dvrd/vcjd/factsheet_nvcjd. htm. Accessed February 17, 2015.

2. Prusiner SB. Prion diseases and the BSE crisis. Science. 1997;278(5336):245-251.

3. Head MW. Human prion diseases: molecular, cellular and population biology. Neuropathology. 2013;33(3):221-236.

4. Miller MW, Williams ES. Prion disease: horizontal prion transmission in mule deer. Nature. 2003;425(6953):35-36.

5. Garruto R, et al. Risk behaviors in a rural com- munity with a known point-source exposure to chronic wasting disease. Environ Health. 2008;24(7):31.

6. Angers RC, et al. Prions in skeletal muscles of deer with chronic wasting disease. Science. 2006;311(5764):1117.

7. Race B, Meade-White K, Oldstone MB, Race R, Chesebro B. Detection of prion infectivity in fat tissues of scrapie-infected mice. PLoS Pathog. 2008;4(12):e1000232.

8. Abrams JY, Maddox RA, Harvey AR, Schonberger LB, Belay ED. Travel history, hunting, and venison consumption related to prion disease expo- sure, 2006-2007 FoodNet Population Survey. JAm Diet Assoc. 2011;111(6):858-863.

9. Kong Q, et al. Chronic wasting disease of elk: transmissibility to humans examined by transgenic mouse models. J Neurosci. 2005;25(35):7944-7949.

10. Tamguney G, et al. Transmission of elk and deer prions to transgenic mice.J Virol. 2006;80(18):9104-9114.

11. Sandberg MK, et al. Chronic wasting disease prions are not transmissible to transgenic mice overexpressing human prion protein. J Gen Virol. 2010;91(pt 10):2651-2657. 
12. Wilson R, et al. Chronic wasting disease and atypical forms of bovine spongiform encephalopathy and scrapie are not transmissible to mice expressing wild-type levels of human prion protein. J Gen Virol. 2012;93(pt 7):1624-1629.

13. Barria MA, Ironside JW, Head MW. Exploring the zoonotic potential of animal prion diseases: in vivo and in vitro approaches. Prion. 2014;8(1):85-91.

14. Barria MA, Telling GC, Gambetti P, Mastrianni JA, Soto C. Generation of a new form of human $\operatorname{PrP}(\mathrm{Sc})$ in vitro by interspecies transmission from cervid prions. J Biol Chem. 2011;286(9):7490-7495.

15. Marsh RF, Kincaid AE, Bessen RA, Bartz JC. Interspecies transmission of chronic wasting disease prions to squirrel monkeys (Saimiri sciureus). J Virol. 2005;79(21):13794-13796.

16. Race B, Meade-White KD, Phillips K, Striebel J, Race R, Chesebro B. Chronic wasting disease agents in nonhuman primates. Emerg Infect Dis. 2014;20(5):833-837.

17. Barria MA, et al. Molecular barriers to zoonotic transmission of prions. Emerg Infect Dis. 2014;20(1):88-97.

18. Raymond GJ, et al. Evidence of a molecular barrier limiting susceptibility of humans, cattle and sheep to chronic wasting disease. $E M B O J$. 2000;19(17):4425-4430.

19. Luers L, et al. Seeded fibrillation as molecular basis of the species barrier in human prion diseases. PLoS One. 2013;8(8):e72623.

20. Vanik DL, Surewicz KA, Surewicz WK. Molecular basis of barriers for interspecies transmissibility of mammalian prions. Mol Cell. 2004;14(1):139-145.

21. Riek R, Hornemann S, Wider G, Billeter M, Glockshuber R, Wüthrich K. NMR structure of the mouse prion protein domain $\operatorname{PrP}$ (121-231). Nature. 1996;382(6587):180-182.

22. Billeter M, Riek R, Wider G, Hornemann S, Glockshuber R, Wüthrich K. Prion protein NMR structure and species barrier for prion diseases. Proc Natl Acad Sci U S A. 1997;94(14):7281-7285.

23. Wopfner F, et al. Analysis of 27 mammalian and 9 avian PrPs reveals high conservation of flexible regions of the prion protein. J Mol Biol. 1999;289(5):1163-1178.

24. Premzl M, et al. The prion protein gene: identifying regulatory signals using marsupial sequence. Gene. 2005;349:121-134.

25. Atarashi R, Sim VL, Nishida N, Caughey B, Katamine $S$. Prion strain-dependent differences in conversion of mutant prion proteins in cell culture. J Virol. 2006;80(16):7854-7862.

26. Geoghegan JC, Miller MB, Kwak AH, Harris BT, Supattapone S. Trans-dominant inhibition of prion propagation in vitro is not mediated by an accessory cofactor. PLOS Pathog. 2009;5(7):e1000535.

27. Kaneko K, et al. Evidence for protein $X$ binding to a discontinuous epitope on the cellular prion protein during scrapie prion propagation. Proc Natl Acad Sci U S A. 1997;94(19):10069-10074.

28. Kurt TD, Jiang L, Bett C, Eisenberg D, Sigurdson CJ. A proposed mechanism for the promotion of prion conversion involving a strictly conserved tyrosine residue in the $\beta 2-\alpha 2$ loop of PrPC. J Biol Chem. 2014;289(15):10660-10667.

29. Kurt TD, et al. Prion Transmission Prevented by Modifying the beta2-alpha2 Loop Structure of Host PrPC. J Neurosci. 2014;34(3):1022-1027.

30. Perrier V, et al. Dominant-negative inhibition of prion replication in transgenic mice. Proc Natl Acad Sci U S A. 2002;99(20):13079-13084.

31. Safar JG, et al. Conserved properties of human and bovine prion strains on transmission to guinea pigs. Lab Invest. 2011;91(9):1326-1336.

32. Peretz D, et al. Strain-specified relative conformational stability of the scrapie prion protein. Protein Sci. 2001;10(4):854-863.

33. Saborio GP, Permanne B, Soto C. Sensitive detection of pathological prion protein by cyclic amplification of protein misfolding. Nature. 2001;411(6839):810-813.

34. Mays CE, et al. In vitro amplification of misfolded prion protein using lysate of cultured cells. PLoS One. 2011;6(3):e18047.

35. Christen B, Hornemann S, Damberger FF, Wüthrich K. Prion protein NMR structure from tammar wallaby (Macropus eugenii) shows that the beta2alpha2 loop is modulated by long-range sequence effects. J Mol Biol. 2009;389(5):833-845.

36. Watts JC, Giles K, Patel S, Oehler A, DeArmond SJ, Prusiner SB. Evidence that bank vole PrP is a universal acceptor for prions. PLoS Pathog. 2014;10(4):e1003990.

37. Will RG, et al. A new variant of CreutzfeldtJakob disease in the UK. Lancet. 1996;347(9006):921-925.

38. Latest NCJDRSU CJD Monthly Statistics. National CJD Research \& Surveillance Unit web site. http://www.cjd.ed.ac.uk/documents/figs.pdf. Accessed January 26, 2015

39. Collinge J, Sidle KC, Meads J, Ironside J, Hill AF. Molecular analysis of prion strain variation and the aetiology of 'new variant' CJD. Nature. 1996;383(6602):685-690.

40. Bruce ME, et al. Transmissions to mice indicate that 'new variant' CJD is caused by the BSE agent. Nature. 1997;389(6650):498-501.

41. Pattison IH, Jones KM. Modification of a strain of mouse-adapted scrapie by passage through rats. Res Vet Sci. 1968;9(5):408-410.

42. Kimberlin RH, Walker C. Characteristics of a short incubation model of scrapie in the golden hamster. J Gen Virol. 1977;34(2):295-304.

43. Scott M, et al. Propagation of prions with artificial properties in transgenic mice expressing chimeric PrP genes. Cell. 1993;73(5):979-988.

44. Piening N, et al. Conversion efficiency of bank vole prion protein in vitro is determined by residues 155 and 170 , but does not correlate with the high susceptibility of bank voles to sheep scrapie in vivo. $J$ Biol Chem. 2006;281(14):9373-9384.

45. La Spada AR, Wilson EM, Lubahn DB, Harding AE, Fischbeck KH. Androgen receptor gene mutations in X-linked spinal and bulbar muscular atrophy. Nature. 1991;352(6330):77-79.

46. Osherovich LZ, Weissman JS. Multiple Gln/ Asn-rich prion domains confer susceptibility to induction of the yeast [PSI(+)] prion. Cell. 2001;106(2):183-194.
47. Perutz MF, Pope BJ, Owen D, Wanker EE, Scherzinger E. Aggregation of proteins with expanded glutamine and alanine repeats of the glutamine-rich and asparagine-rich domains of Sup 35 and of the amyloid beta-peptide of amyloid plaques. Proc Natl Acad Sci U S A. 2002;99(8):5596-5600.

48. Di Bari MA, et al. The bank vole (Myodes glareolus) as a sensitive bioassay for sheep scrapie. J Gen Virol. 2008;89(pt 12):2975-2985.

49. Di Bari MA, et al. Chronic wasting disease in bank voles: characterisation of the shortest incubation time model for prion diseases. PLoS Pathog. 2013;9(3):e1003219.

50. Nonno R, et al. Efficient transmission and characterization of Creutzfeldt-Jakob disease strains in bank voles. PLoS Pathog. 2006;2(2):e12.

51. Agrimi U, et al. Prion protein amino acid determinants of differential susceptibility and molecular feature of prion strains in mice and voles. PLoS Pathog. 2008;4(7):e1000113.

52. Raymond GJ, et al. Transmission and adaptation of chronic wasting disease to hamsters and transgenic mice: evidence for strains. J Virol. 2007;81(8):4305-4314.

53. Kimberlin RH, Cole S, Walker CA. Transmissible mink encephalopathy (TME) in Chinese hamsters: identification of two strains of TME and comparisons with scrapie. Neuropathol Appl Neurobiol. 1986;12(2):197-206.

54. Chandler RL, Turfrey BA. Inoculation of voles, Chinese hamsters, gerbils and guineapigs with scrapie brain material. Res Vet Sci. 1972;13(3):219-224.

55. Hunter N, Foster JD, Goldmann W, Stear MJ, Hope J, Bostock C. Natural scrapie in a closed flock of Cheviot sheep occurs only in specific PrP genotypes. Arch Virol. 1996;141(5):809-824.

56. Hunter N, Goldmann W, Benson G, Foster JD, Hope J. Swaledale sheep affected by natural scrapie differ significantly in PrP genotype frequencies from healthy sheep and those selected for reduced incidence of scrapie. J Gen Virol. 1993;74(pt 6):1025-1031.

57. Aguilar-Calvo P, et al. Role of the goat K222$\operatorname{Pr} \mathrm{P}(\mathrm{C})$ polymorphic variant in prion infection resistance. JVirol. 2014;88(5):2670-2676.

58. Tessier PM, Lindquist S. Prion recognition elements govern nucleation, strain specificity and species barriers. Nature. 2007;447(7144):556-561.

59. Sigurdson CJ, et al. A molecular switch controls interspecies prion disease transmission in mice. JClin Invest. 2010;120(7):2590-2599.

60. Sawaya MR, et al. Atomic structures of amyloid cross-beta spines reveal varied steric zippers. Nature. 2007;447(7143):453-457.

61. Apostol MI, Sawaya MR, Cascio D, Eisenberg D. Crystallographic studies of prion protein (PrP) segments suggest how structural changes encoded by polymorphism at residue 129 modulate susceptibility to human prion disease. J Biol Chem. 2010;285(39):29671-29675.

62. Apostol MI, Wiltzius JJ, Sawaya MR, Cascio D, Eisenberg D. Atomic structures suggest determinants of transmission barriers in mammalian prion disease. Biochemistry. 2011;50(13):2456-2463.

63. Horiuchi M, Baron GS, Xiong LW, Caughey B. Inhibition of interactions and interconversions 
of prion protein isoforms by peptide fragments from the C-terminal folded domain. J Biol Chem. 2001;276(18):15489-15497.

64. Sievers SA, et al. Structure-based design of nonnatural amino-acid inhibitors of amyloid fibril formation. Nature. 2011;475(7354):96-100.

65. Fischer $\mathrm{M}$, et al. Prion protein (PrP) with amino-proximal deletions restoring susceptibility of PrP knockout mice to scrapie. ЕMBO J. 1996;15(6):1255-1264.
66. Polymenidou M, et al. The POM monoclonals: a comprehensive set of antibodies to nonoverlapping prion protein epitopes. PLoS One. 2008;3(12):e3872.

67. Sigurdson CJ, et al. Strain fidelity of chronic wasting disease upon murine adaptation. J Virol. 2006;80(24):12303-12311.

68. Wadsworth JD, et al. Tissue distribution of protease resistant prion protein in variant CJD using a highly sensitive immuno-blotting assay. Lancet.
2001;358(9277):171-180.

69. Castilla J, Morales R, Saa P, Barria M, Gambetti P, Soto C. Cell-free propagation of prion strains. EMBO J. 2008;27(19):2557-2566.

70. Wiltzius JJ, et al. Molecular mechanisms for protein-encoded inheritance. Nat Struct Mol Biol. 2009;16(9):973-978.

71. Nelson R, et al. Structure of the cross- $\beta$ spine of amyloid-like fibrils. Nature. 2005;435(7043):773-778. 